\title{
Microstructures of Pearlite and Martensite Transformed from Ultrafine-Grained Austenite Fabricated through Cyclic Heat Treatment in Medium Carbon Steels
}

\author{
Akinobu Shibata*1, Shohei Daido*2, Daisuke Terada and Nobuhiro Tsuji \\ Department of Materials Science and Engineering, Kyoto University, Kyoto 606-8501, Japan
}

This study investigated the microstructures of pearlite and martensite transformed from ultrafine-grained austenite in $0.45 \mathrm{C}$ steel and $\mathrm{V}$ added $0.45 \mathrm{C}$ steel. The mean prior austenite grain sizes were refined to be $4.5 \mu \mathrm{m}$ in the $0.45 \mathrm{C}$ specimen and $2.4 \mu \mathrm{m}$ in the $\mathrm{V}$-added $0.45 \mathrm{C}$ specimen through cyclic heat treatment of austenitizing and water quenching, i.e., repetition of martensite $\leftrightarrow$ austenite transformations. The austenite with various grain sizes was either air-cooled or water-quenched to cause pearlitic or martensitic transformation, respectively. The fragmented lamellar structure and isolated cementite particles having particulate morphology were observed in the pearlite transformed from the ultrafine-grained austenite. Results indicated that the ferrite and cementite formed during eutectoid transformation from the ultrafine-grained austenite were not necessary to grow cooperatively maintaining lamellar shape. The packet size in lath martensite was refined significantly accompanied by decreasing of the austenite grain size, since several different variants of martensite were formed from different segments of austenite grain boundaries even when the austenite grain size was fine. In contrast, the block size did not depend on the austenite grain size. [doi:10.2320/matertrans.MH201312]

(Received March 4, 2013; Accepted April 22, 2013; Published June 7, 2013)

Keywords: phase transformation, pearlite, martensite, austenite, ultrafine-grained structure, cyclic heat treatment, medium carbon steel

\section{Introduction}

Pearlite and lath martensite are practically important transformation products in steels. The pearlite is formed by diffusional eutectoid transformation in carbon steels. The pearlite usually has the lamellar morphology where thin plates of ferrite and cementite align alternatively, which is formed by cooperative growth of ferrite and cementite phases during eutectoid transformation. The lath martensite formed by displacive (diffusionless) transformation appears in low and medium carbon steels. The microstructure of lath martensite consists of several structural units with different scales, i.e., lath, block, packet and prior austenite grain. ${ }^{1,2)}$ The lath is a single crystal of martensite with thickness of approximately $0.2 \mu \mathrm{m}$. The block contains many laths having nearly the identical orientation (or variant). The packet consists of several blocks with almost the same habit plane of austenite. Usually several packets appear in a prior austenite grain.

It is well known that parent austenite grain size affects phase transformation behaviors significantly. In particular, several groups reported that phase transformations from ultrafine-grained austenite with grain size smaller than $1 \mu \mathrm{m}$ exhibit different manners compared with those from conventionally coarse-grained austenite. ${ }^{3-7)}$ Tadaki et al. ${ }^{3,4)}$ studied the martensitic transformation behavior from powder particles of austenite having nanometer-sizes in $\mathrm{Fe}-\mathrm{Ni}$ alloys. Their results indicated that the martensitic transformation start temperature (Ms) of the nano powder particles of austenite was much lower than that in the bulky specimen with coarse-grained austenite. The high thermal stability of bulky polycrystalline austenite with ultrafine grains against martensitic transformation was also confirmed in an $\mathrm{Fe}-\mathrm{Ni}$ alloy ${ }^{5)}$ and an austenitic stainless steel. ${ }^{6}$ In addition, it was reported that the crystallographic features, such as variant

${ }^{* 1}$ Corresponding author, E-mail: shibata.akinobu.5x@kyoto-u.ac.jp

${ }^{* 2}$ Graduate Student, Kyoto University selection rule and orientation relationship, of martensite transformed from ultrafine-grained austenite were different from those transformed from coarse-grained austenite. ${ }^{6-8)}$

The studies about the phase transformation behaviors from ultrafine-grained austenite mentioned above have been concerned with plate-type martensite in high-alloy austenitic steels or martensite in stainless steels whose transformation temperatures are below room temperature. So far, on the other hand, the transformation behaviors to pearlite and lath martensite from ultrafine-grained austenite at relatively high temperature in, for example, conventional carbon steels have been rarely studied. The present study investigates the microstructures of pearlite and martensite transformed from ultrafine-grained polycrystalline austenite.

\section{Experimental Procedure}

The materials used in the present study are two kinds of medium carbon steels: a $0.45 \mathrm{C}$ steel and a V-added $0.45 \mathrm{C}$ steel where 0.3 mass $\%$ vanadium was added to inhibit grain growth of austenite through pinning by vanadium carbides. The detailed chemical compositions of the steels are shown in Table 1 . The steels were austenitized at $1373 \mathrm{~K}$ for $1.8 \mathrm{ks}$ in vacuum, followed by water quenching. The austenitized specimens were used as starting materials. The austenite grain sizes of the specimens were reduced through repetition of martensite $\leftrightarrow$ austenite transformations proposed by Grange, ${ }^{9,10)}$ i.e., cyclic heat treatment of austenitizing at $1073 \mathrm{~K}$ for $60 \mathrm{~s}$ in a salt bath and water quenching. In the last cycle of the heat treatment, the specimens were cooled in air

Table 1 Chemical compositions of the steels investigated.

\begin{tabular}{lcccccccc}
\hline & \multicolumn{1}{c}{} & \multicolumn{1}{c}{} & \multicolumn{3}{c}{ (mass\%) } \\
\hline 0.45C & 0.44 & $<$ & Vn & Si & P & S & Al & Fe \\
V-added 0.45C & 0.46 & 0.30 & 0.84 & 0.26 & 0.014 & 0.018 & 0.033 & bal. \\
\hline
\end{tabular}



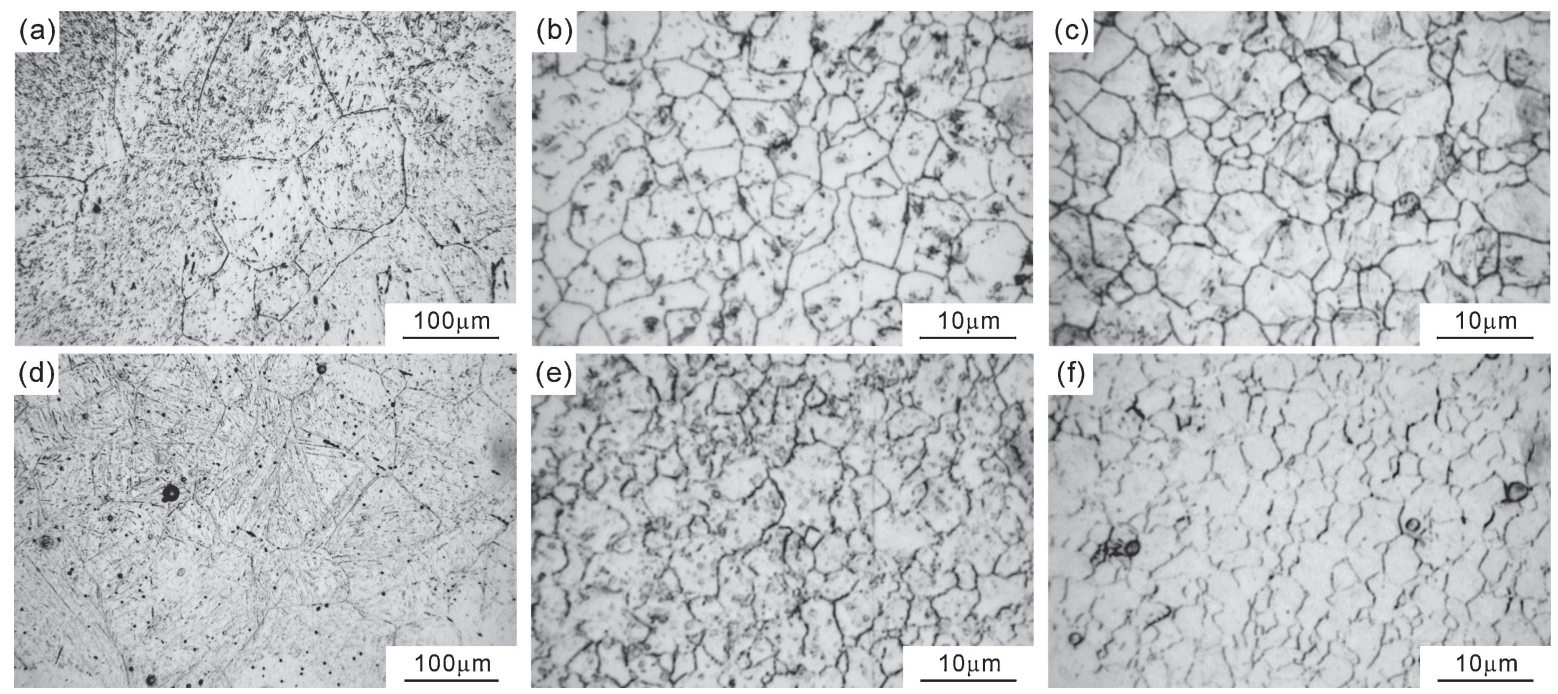

Fig. 1 Optical microscopy images of (a)-(c) the $0.45 \mathrm{C}$ specimens and (d)-(f) the V-added $0.45 \mathrm{C}$ specimens after various cycles of the heat treatment; (a), (d) before the cyclic heat treatment ( 0 cycle). (b), (e) after 2 cycles of the heat treatment. (c), (f) after 5 cycles of the heat treatment, respectively.

to obtain ferrite-pearlite structures or water quenched to obtain lath martensite structures.

For microstructural observations, the specimens were polished mechanically and electrolytically in a solution of $5 \% \mathrm{HClO}_{4}+95 \% \mathrm{CH}_{3} \mathrm{COOH}$. The mean prior austenite grain sizes were measured by line interception method using the optical microscopy images where the prior austenite grain boundaries in lath martensite were revealed by etching using a saturated picric acid solution. The microstructure of pearlite was observed by scanning electron microscopy (SEM, using FEI XL30S-FEG) after etching in a 5\% nital. The microstructure of lath martensite was crystallographically characterized by electron backscatter diffraction (EBSD) analyzer in the SEM operated at $15 \mathrm{kV}$. The EBSD measurement and analysis were performed with the TSL OIM Data Collection program and the TSL OIM Analysis program.

\section{Results and Discussion}

Figure 1 shows optical microscopy images of (a)-(c) the $0.45 \mathrm{C}$ specimens and (d)-(f) the V-added $0.45 \mathrm{C}$ specimens after the cyclic heat treatment. The microstructures of the specimens are fully martensite, but we can clearly observe the prior austenite grain boundaries in Fig. 1 by suitable etching. The prior austenite grains were significantly refined through the cyclic heat treatment. The martensite structure usually involves a high density of lattice defects, such as high angle boundaries (packet boundaries and block boundaries) and dislocations. These lattice defects acted as nucleation sites for the reverse transformation to austenite, resulting in the grain refinement of austenite through the cyclic heat treatment. Figure 2 represents change in the mean prior austenite grain sizes as a function of the number of heat treatment cycles. After 1 cycle of the heat treatment, the mean prior austenite grain sizes were reduced significantly from $d_{\gamma}=109 \mu \mathrm{m}$ of the starting specimen to $d_{\gamma}=8.3 \mu \mathrm{m}$ in the $0.45 \mathrm{C}$ specimen and from $d_{\gamma}=80 \mu \mathrm{m}$ to $d_{\gamma}=4.3 \mu \mathrm{m}$ in the V-added $0.45 \mathrm{C}$ specimen. However, further cycles of the heat treatment did

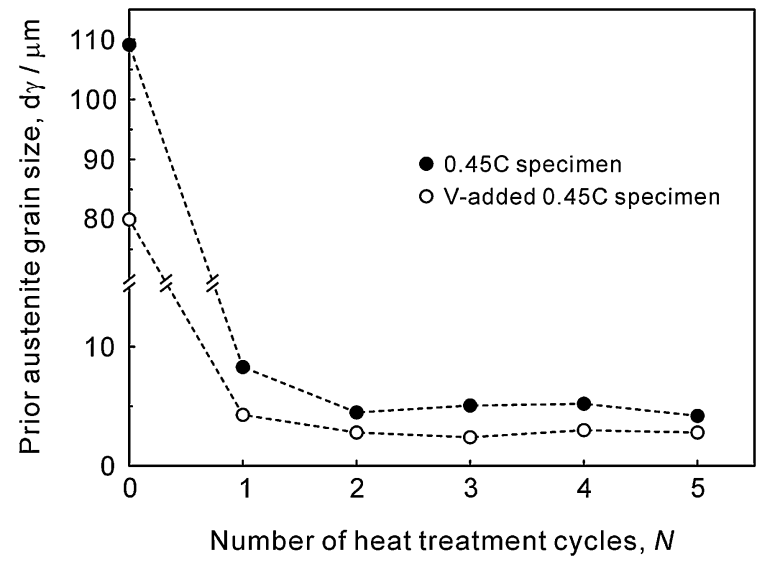

Fig. 2 Change in the mean prior austenite grain sizes as a function of the number of heat treatment cycles (solid circles: the $0.45 \mathrm{C}$ specimens, open circles: the V-added $0.45 \mathrm{C}$ specimens).

not change the prior austenite grain sizes so much. This indicates that refinement of austenite grain by nucleation of many austenite nuclei and coarsening of austenite grain through grain growth after completion of reverse transformation become comparable after reaching a certain critical prior austenite grain size. The minimum mean prior austenite grain size in the $\mathrm{V}$-added $0.45 \mathrm{C}$ specimen obtained through the cyclic heat treatment was $d_{\gamma}=2.4 \mu \mathrm{m}$ after 3 cycles, much smaller than that in the $0.45 \mathrm{C}$ specimen $\left(d_{\gamma}=4.5 \mu \mathrm{m}\right.$ after 2 cycles). This is because vanadium carbides significantly suppressed the grain growth of austenite during the heat treatment.

Figures 3(a) and 3(c) are SEM images of the air-cooled $0.45 \mathrm{C}$ and $\mathrm{V}$-added $0.45 \mathrm{C}$ specimens with coarse-grained austenite $\left(d_{\gamma}=109 \mu \mathrm{m}\right.$ for $0.45 \mathrm{C}$ specimen and $d_{\gamma}=80 \mu \mathrm{m}$ for $\mathrm{V}$-added $0.45 \mathrm{C}$ specimen), respectively. Bright and dark areas correspond to cementite and ferrite, respectively. We can observe the pearlites consisting of clear lamellar structures. As shown in Figs. 3(b) and 3(d), on the other 

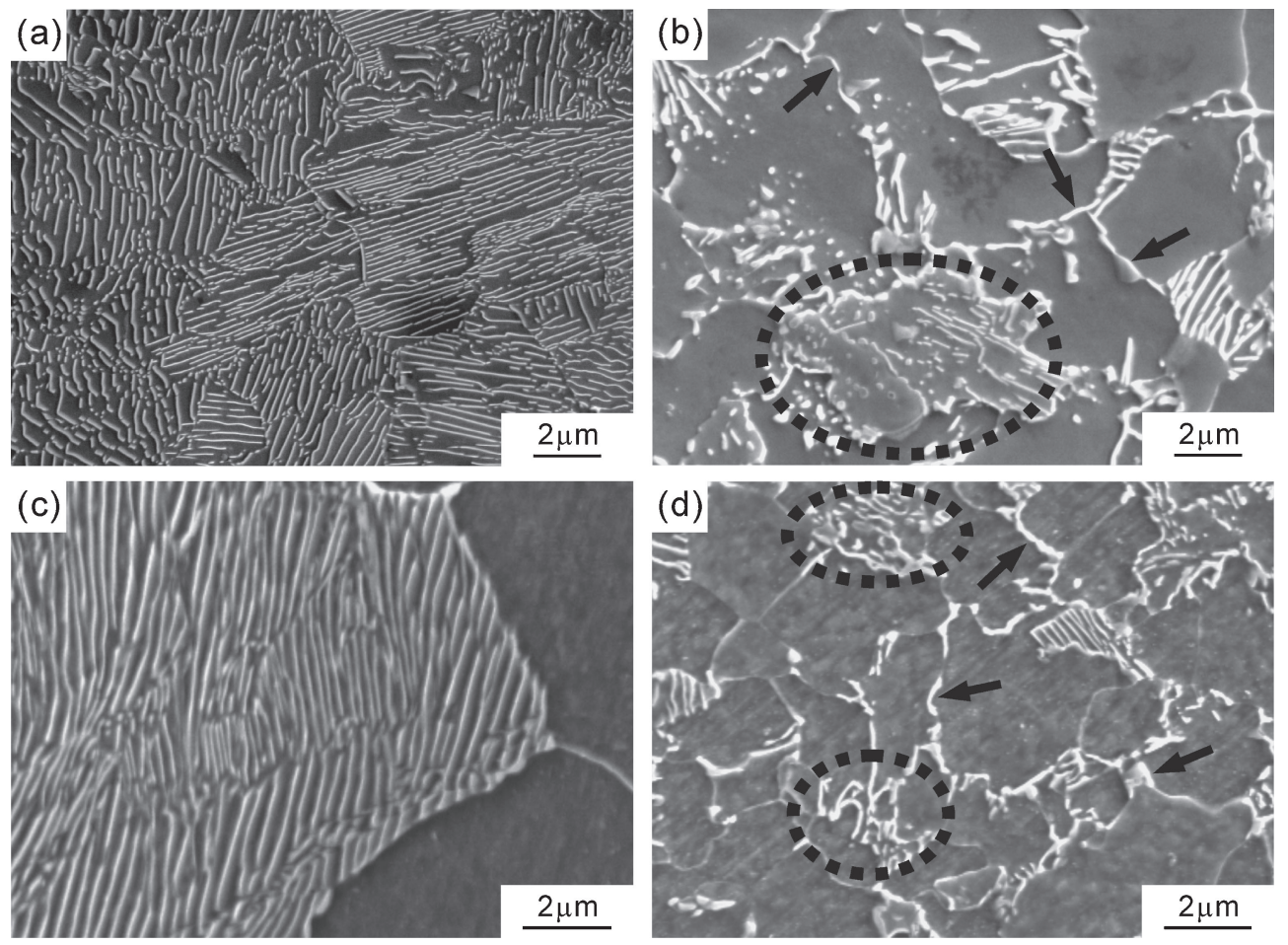

Fig. 3 SEM images of pearlites transformed from (a) the coarse-grained austenite in the $0.45 \mathrm{C}$ specimen (before the cyclic heat treatment, $d_{\gamma}=109 \mu \mathrm{m}$ ), (b) the ultrafine-grained austenite in the $0.45 \mathrm{C}$ specimen (after 2 cycles of the heat treatment, $d_{\gamma}=4.5 \mu \mathrm{m}$ ), (c) the coarsegrained austenite in the $\mathrm{V}$-added $0.45 \mathrm{C}$ specimen (before the cyclic heat treatment, $d_{\gamma}=80 \mu \mathrm{m}$ ) and (d) the ultrafine-grained austenite in the $\mathrm{V}$-added $0.45 \mathrm{C}$ specimen (after 3 cycles of the heat treatment, $d_{\gamma}=2.4 \mu \mathrm{m}$ ), respectively.

hand, the lamellar structures of pearlites tend to be fragmented and several cementite particles having particulate morphology are isolated (indicated by dotted circles) when the austenite grain sizes were refined to be $d_{\gamma}=4.5 \mu \mathrm{m}$ (0.45C specimen (Fig. 3(b)) and $d_{\gamma}=2.4 \mu \mathrm{m}$ (V-added $0.45 \mathrm{C}$ specimen (Fig. 3(d)). In addition, the measured volume fractions of pearlite transformed from the ultrafinegrained austenite are 0.51 (0.45C specimen (Fig. 3(b)) and 0.21 (V-added $0.45 \mathrm{C}$ specimen (Fig. 3(d)), which are smaller than the value of 0.58 expected from the $\mathrm{Fe}-\mathrm{C}$ binary equilibrium phase diagram. This might be due to the fact that some cementite particles are observed on the ferrite/ ferrite grain boundaries as indicated by arrows in Figs. 3(b) and 3(d).

Previous studies ${ }^{11-13)}$ have also observed the fragmented pearlite microstructures transformed from ultrafine-grained austenite. Furuhara et al. ${ }^{12)}$ proposed that the formation of the fragmented pearlite in a V-added eutectoid steel was due to the coarse undissolved carbides in austenite. The heat treatment of the present study was heated up rapidly from martensite to austenite and water-quenched from austenite to martensite, without any tempering treatments. Accordingly, the amount of the undissolved carbides in the austenite state of the present $0.45 \mathrm{C}$ specimen must be few or almost zero. Although the austenite of the $\mathrm{V}$-added $0.45 \mathrm{C}$ specimen contains vanadium carbides, the carbides are expected to be very fine. Because the fragmented pearlites are observed in both $0.45 \mathrm{C}$ specimen (Fig. 3(b)) and V-added $0.45 \mathrm{C}$ specimen (Fig. 3(d)) having fine austenite grains, it can be said that the ultrafine-grained austenite structure itself causes the fragmented pearlite structures observed in Figs. 3(b) and 3(d). In general, pearlite exhibits lamellar structure of ferrite and cementite to reduce the diffusion distance of iron and carbon atoms during eutectoid transformation. When the austenite grains are ultrafine, the distance between neighboring pearlite colonies nucleated on the austenite grain boundaries is very short. It should be also noted that high density of austenite grain boundaries in the ultrafine-grained microstructures act as fast paths for diffusion. Under such a situation, the diffusion field of carbon around the pearlite colonies might be overlapped and become rather uniform. As a result, ferrite and cementite are not necessary to grow cooperatively keeping lamellar morphologies. This is one of the possible reasons for the formation of the fragmented pearlite structures from the ultrafine-grained austenite.

Figures 4(a) and 4(c) are EBSD orientation maps of the water-quenched $0.45 \mathrm{C}$ and $\mathrm{V}$-added $0.45 \mathrm{C}$ specimens with coarse-grained austenite $\left(d_{\gamma}=109 \mu \mathrm{m}\right.$ in the $0.45 \mathrm{C}$ specimen and $d_{\gamma}=80 \mu \mathrm{m}$ in the $\mathrm{V}$-added $0.45 \mathrm{C}$ specimen). The microstructures exhibit typical lath martensite structures consisting of blocks and packets inside the prior austenite grains. The block boundaries, packet boundaries and prior austenite grain boundaries identified through variant analysis are drawn in black lines, thick black lines and black dotted lines, respectively. The measured packet and block sizes are $d_{\text {packet }}=14 \mu \mathrm{m}$ and $d_{\text {block }}=1.0 \mu \mathrm{m}$ in the $0.45 \mathrm{C}$ specimen (Fig. 4(a)), $d_{\text {packet }}=23 \mu \mathrm{m}$ and $d_{\text {block }}=0.6 \mu \mathrm{m}$ in the $\mathrm{V}$ added $0.45 \mathrm{C}$ specimen (Fig. 4(c)), respectively. Figures 4(b) and 4(d) show the orientation maps of martensite transformed from ultrafine-grained austenite in the $0.45 \mathrm{C}$ specimen $\left(d_{\gamma}=\right.$ $4.5 \mu \mathrm{m})$ and the $\mathrm{V}$-added $0.45 \mathrm{C}$ specimen $\left(d_{\gamma}=2.8 \mu \mathrm{m}\right)$, respectively. The measured packet and block sizes are 

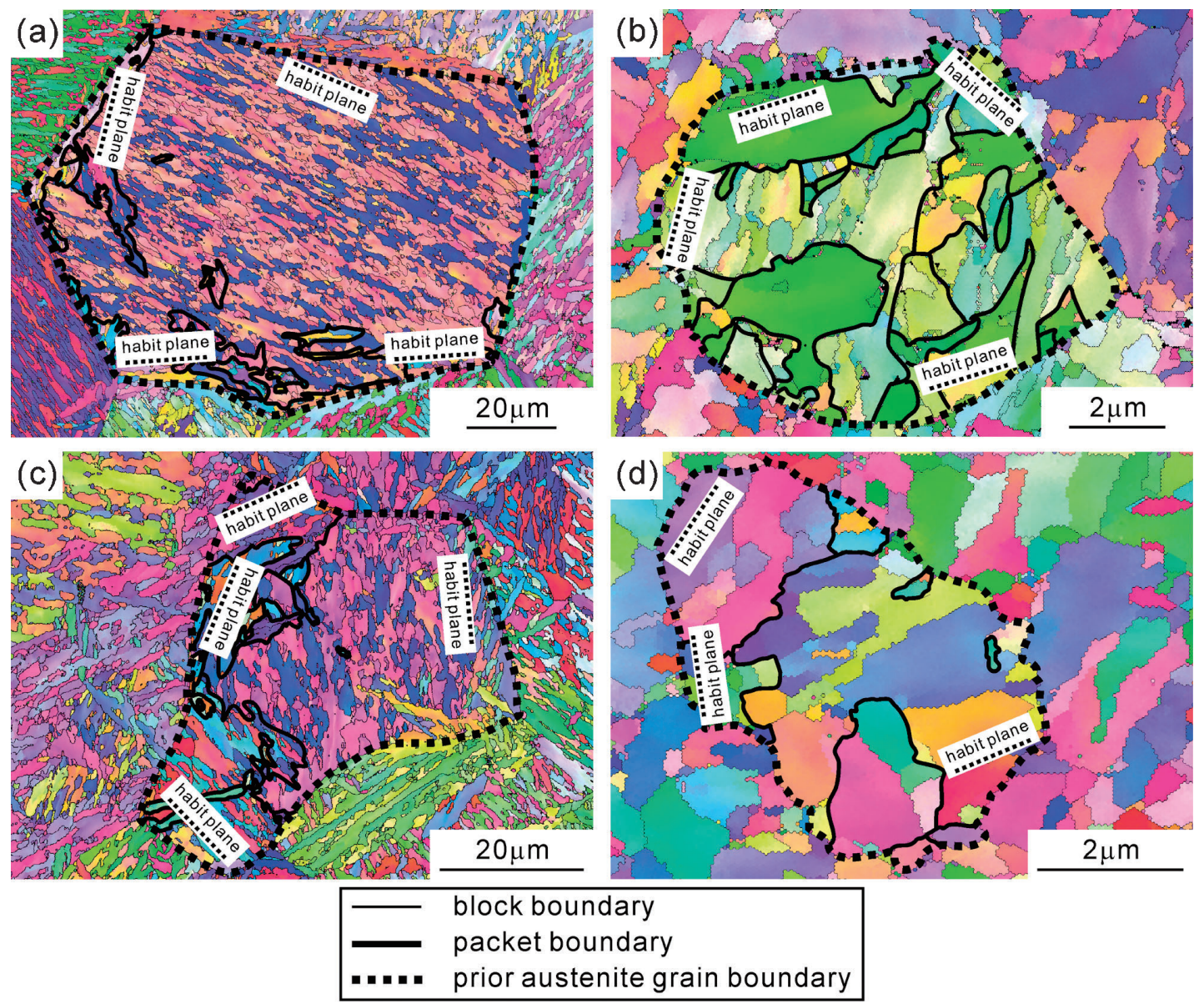

Fig. 4 EBSD orientation maps of lath martensite transformed from (a) the coarse-grained austenite in the $0.45 \mathrm{C}$ specimen (before the cyclic heat treatment, $d_{\gamma}=109 \mu \mathrm{m}$ ), (b) the ultrafine-grained austenite in the $0.45 \mathrm{C}$ specimen (after 2 cycles of the heat treatment, $d_{\gamma}=4.5 \mu \mathrm{m}$ ), (c) the coarse-grained austenite in the $\mathrm{V}$-added $0.45 \mathrm{C}$ specimen (before the cyclic heat treatment, $\left.d_{\gamma}=80 \mu \mathrm{m}\right)$ and (d) the ultrafine-grained austenite in the $\mathrm{V}$-added $0.45 \mathrm{C}$ specimen (after 5 cycles of the heat treatment, $d_{\gamma}=2.8 \mu \mathrm{m}$ ), respectively. The block boundaries, packet boundaries and prior austenite grain boundaries are identified by black lines, thick black lines and black dotted lines, respectively. The traces of habit planes of the martensite variants near prior austenite grain boundaries determined through crystallographic analysis are also indicated.

$d_{\text {packet }}=1.3 \mu \mathrm{m}$ and $d_{\text {block }}=0.4 \mu \mathrm{m}$ in the $0.45 \mathrm{C}$ specimen (Fig. $4(\mathrm{~b})), d_{\text {packet }}=2.0 \mu \mathrm{m}$ and $d_{\text {block }}=0.4 \mu \mathrm{m}$ in the $\mathrm{V}$ added $0.45 \mathrm{C}$ specimen (Fig. 4(d)), respectively. As the austenite grain size decreases, the packet size decreases significantly but the block size decreases slightly. Additionally, the blocks transformed from the ultrafine-grained austenite tend to exhibit rather equiaxed morphology compared with those transformed from the coarse-grained austenite. Takaki et al. ${ }^{6}$ ) reported that the ultrafine-grained austenite with grain sizes smaller than $10 \mu \mathrm{m}$ transformed to single variant martensite or single packet (variants of martensite with the identical habit plane) in an austenitic stainless steel. As shown in the EBSD orientation maps of Figs. 4(b) and 4(d), however, the ultrafine-grained austenite with grain sizes of $d_{\gamma}=4.5 \mu \mathrm{m}$ in the $0.45 \mathrm{C}$ specimen and $d_{\gamma}=2.8 \mu \mathrm{m}$ in the $\mathrm{V}$-added $0.45 \mathrm{C}$ specimen still transformed to lath martensites consisting of several martensite variants, i.e., several packets and blocks inside the prior austenite grains.

Morito et al. ${ }^{14)}$ studied the variant selection during isothermal martensitic transformation in an $\mathrm{Fe}-\mathrm{Ni}-\mathrm{Mn}$ alloy. According to their results, martensite variants having habit planes parallel to the austenite grain boundaries are preferentially formed at the austenite grain boundaries. It has been also reported that the martensite variants inside an identical packet have almost the identical habit plane close to the parallel plane in Kurdjumov-Sachs orientation relationship. ${ }^{15,16)}$ We therefore can obtain the orientation of habit plane by drawing $\{110\}$ pole figure of the observed martensite variants. The traces of habit planes of the martensite variants near prior austenite grain boundaries determined through the pole figure analysis are also indicated in Fig. 4. We have found that several martensite variants formed near austenite grain boundaries have habit planes nearly parallel to the austenite grain boundaries even when the austenite grain sizes were decreased to $d_{\gamma}=4.5 \mu \mathrm{m}$ (0.45C specimen) and $d_{\gamma}=2.8 \mu \mathrm{m}$ (V-added $0.45 \mathrm{C}$ specimen) as shown in Figs. 4(b) and 4(d). It can be said, therefore, that several different martensite variants are formed nearby austenite grain boundaries at the early stage of martensitic transformation due to the strong variant selection rule, even when the austenite grain size is ultrafine, which leads to the refinement of packets with decreasing austenite grain sizes. 


\section{Summary}

This paper studied the microstructures of pearlite and lath martensite transformed from ultrafine-grained austenite in medium carbon steels. Unique microstructural features were found in the specimens having ultrafine-grained austenite. The major results obtained are summarized as follows:

(1) By the repetition of martensite $\leftrightarrow$ austenite transformations, the mean prior austenite grain sizes decreased from $d_{\gamma}=109 \mu \mathrm{m}$ to $d_{\gamma}=4.5 \mu \mathrm{m}$ in the $0.45 \mathrm{C}$ steel, and from $d_{\gamma}=80 \mu \mathrm{m}$ to $d_{\gamma}=2.4 \mu \mathrm{m}$ in the $\mathrm{V}$-added $0.45 \mathrm{C}$ steel. The minimum mean prior austenite grain size of the $\mathrm{V}$-added $0.45 \mathrm{C}$ specimen was smaller than that of the $0.45 \mathrm{C}$ specimen because vanadium carbides suppressed the grain growth of austenite.

(2) With decreasing austenite grain size, the pearlite lamellar structure tended to be fragmented and some cementite particles with particulate morphologies were isolatedly formed. When the austenite grains are ultrafine, ferrite and cementite formed during eutectoid transformation are not necessary to grow cooperatively keeping lamellar morphologies, because the diffusion field of carbon in front of pearlite colonies nucleated on grain boundaries in the ultrafine-grained austenite structures is expected to be overlapped and become uniform.

(3) The packets in lath martensite were greatly refined with decreasing austenite grain size. In contrast, the block size did not depend so much on the austenite grain size. Several packets were formed inside one prior austenite grain even when the austenite grain size was ultrafine. This was because several different martensite variants were nucleated near austenite grain boundaries maintaining a strong variant selection rule.

\section{Acknowledgement}

This study was financially supported by the Grant-in-Aid for Scientific Research on Innovative Area, "Bulk Nanostructured Metals" (area No. 2201), the Grant-in-Aid for Scientific Research (A) (No. 24246114), the Grant-in-Aid for Challenging Exploratory Research (No. 24656440), and the Elements Strategy Initiative for Structural Materials (ESISM), all through the Ministry of Education, Culture, Sports, Science and Technology (MEXT), Japan (contact No. 22102002). AS and NT were also supported by the Iron and Steel Institute of Japan (ISIJ). The authors greatly appreciate all the supports.

\section{REFERENCES}

1) A. R. Marder and G. Krauss: Trans. ASM 60 (1967) 651-660.

2) J. M. Marder and A. R. Marder: Trans. ASM 62 (1969) 1-10.

3) T. Tadaki, Y. Murai, A. Koreeda, Y. Nakata and Y. Hirotsu: Mater. Sci. Eng. A 217-218 (1996) 235-238.

4) K. Asaka, Y. Hirotsu and T. Tadaki: Mater. Sci. Eng. A 273-275 (1999) 262-265.

5) H. Kitahara, N. Tsuji and Y. Minamino: Mater. Sci. Eng. A 438-440 (2006) 233-236.

6) S. Takaki, K. Fukunaga, J. Syarif and T. Tsuchiyama: Mater. Trans. 45 (2004) 2245-2251.

7) A. Shibata, H. Jafarian and N. Tsuji: Mater. Trans. 53 (2012) 81-86.

8) H. Jafarian, E. Borhani, A. Shibata and N. Tsuji: J. Alloy. Compd. in press.

9) R. A. Grange: Trans. Q. ASM 59 (1966) 26-48.

10) R. A. Grange: Metall. Trans. 2 (1971) 65-78.

11) Y. Adachi, T. Tomida and S. Hinotani: Tetsu-to-Hagané 85 (1999) 620627.

12) T. Furuhara, K. Kikumoto, H. Saito, T. Sekine, T. Ogawa, S. Morito and T. Maki: ISIJ Int. 48 (2008) 1038-1045.

13) Y. Liu, T. He, G. Peng and F. Lian: Metall. Trans. A 42 (2011) 21442152.

14) S. Morito, J. Nishikawa, T. Ohba, T. Furuhara and T. Maki: Proc. Int. Conf. on Martensitic Transformations, ed. by G. B. Olson, D. S. Lieberman and A. Saxena, (The Minerals, Metals \& Materials Society (TMS), 2008) pp. 649-653.

15) S. Morito, H. Tanaka, R. Konishi, T. Furuhara and T. Maki: Acta Mater. 51 (2003) 1789-1799.

16) S. Morito, X. Huang, T. Furuhara and T. Maki: Acta Mater. 54 (2006) 5323-5331. 